\title{
氞标記化合物的合成、測量(液体閃㮡計数) 及在葯理学硎究中的应用
}

\author{
宋 振 玉 \\ (中国医学科学院䓎物研究所)
}

应用放射性元素标記的化合物大大方便 了䒺理学的研究。用化学合成法或生物合成 法使 $\mathrm{C}^{14} 、 \mathrm{~S}^{35} 、 \mathrm{I}^{131}$ 或 $\mathrm{P}^{32}$ 标記有机化合物，在 过去的二、三年間起了很大的作用。特別是 $\mathrm{C}^{14}$ ，因所有的有机化合物都含碳，且 $\mathrm{C}^{14}$ 的 半衰期很长, 所以 $\mathrm{C}^{14}$ 的应用最为广泛。但 用 $\mathrm{C}^{14}$ 标記化合物有时很困难, 也比較貴, 加之 $\mathrm{C}^{14}$ 的平訔期很长, 难以得到比活性 很高的标記化合物, 应用上受到一定的限制。

随着液体閃湶計数技术的进展，已經可 以很簡单地測量 $\mathrm{H}^{3}$ (郎氞，或称 $\mathrm{T}$ ) 的放射 性。因 $\mathrm{H}^{3}$ 的半衰期較短，每分鈡放出的脉冲 数較 $\mathrm{C}^{14}$ 多。現在已能使一化合物标記到每 毫克分子达几个居里。此外， $\mathrm{H}^{3}$ 的价格低 廉, 且以 $\mathrm{H}^{3}$ 作暴射标記或用氮化物作催化还 原是較方便的使 $\mathrm{H}^{3}$ 进入有机化合物分子的 方法。可以預見，日后应用的标記化合物 中, 用気标記者将占主要地位。

\section{氞标記葯物的合成}

1. 化学合成法和交換法 用気标記䒺物 的常規方法为化学合成法。化学合成法是从 簡单的含氛化合物如 $\mathrm{H}_{2}^{3} 、 \mathrm{H}_{2}^{3} \mathrm{O} 、 \mathrm{NaBH}_{4}^{3}$ 及 $\mathrm{LiAlH}_{4}^{3}$ 等开始, 合成所需要的标記药物。用 这种方法标記葯物，步驟往往很长，而且放
射性的收率不高。但可以在特定位置上标 記, 如使最末一个中間体含一双鍵或可以还 原的基团 (如羰基), 則可使気在最后一步进 入菞物分子內, 这样亦可得比放射性很高的 (可达 58 居里/毫克分子)标記䒺物，一般用 載体氢稀释后, 仍可得每毫克分子数居里的 化合物。具体操作时, 可用气体気作接触还 原，亦可用 $\mathrm{NaBH}_{4}^{3}$ 或 $\mathrm{LiAlH}_{4}^{3}$ 等。気标記的 双氢氯噻嗪就是将氯噻嗪的双鍵以気还原而 得。例如 Sheppard 等 ${ }^{[1]}$ 将氯噻嗪 600 毫克溶 于 10 毫升稀碱( $\mathrm{pH} 8.5$ ), 加 $\mathrm{NaBH}_{4}^{3}$ (比活性 $250 \mu \mathrm{C} / \mu \mathrm{M}) 40$ 毫克, 五小时后 95.5 毫克純 双氢氯噻嗪 $-\mathrm{H}^{3}$ 郎結晶而出, 其比活性为 $12.3 \mu \mathrm{C} / \mu \mathrm{M}_{\text {。 }}$ 若加入非标記的 $\mathrm{NaBH}_{4} 120$ 毫克并使反应进行过夜后, 另有双氯氯噻 嗪 $-\mathrm{H}^{3} 316$ 毫克結晶析出。其比放射性为 $4.5 \mu \mathrm{C} / \mu \mathrm{M}_{\circ}$ 他們还証明，产物中的氛只联 于第 7 位碳原子, 而氮原子上則无氙, 因用 此标記䒺物制备 $\mathrm{N}$-甲基及 $\mathrm{N}$-乙酰基衍生物 时, 关无気脫出, 可能联于氮的気早与溶液 中水的氫原子起交換作用了。另一証据为 产物經強酸水解时, 気郎完全以甲醛形式逸 出。可見采用化学合成法标記䒺物, 必須考 虑反应条件下标記気的不稳定性, 标記気的 确实位置仍須加以証实。另外, 用这种方法 
标記, 如所用氛的放射剂量不大, 可以避免 使标記葯物遭到輻射損害, 操作較为安全。

将拟标記的葯物与带有氛原子的化合物 混合，在有适宜催化剂的情况下，氞可以与 拟标記葯物的氫起交換作用。但是，用这种 方法, 氞只进到較不稳定的位置, 只有当能 将交換所得的标記綮物很快轉化为稳定形式 后, 才能应用。应該指出, 用交換法可以获 得各种极有用的标記中間体，这对合成标記 药物是很方便的。Parke 等 ${ }^{[2]}$ 所用的甘草酸一 $\mathrm{H}^{3}$ 就是用催化交換法制备的。

2. 生物合成法 除了化学合成法外, 有 时策用生物合成法制备含放射性同位素的菞 物，特別是一些构造复杂，目前人工化学合 成劣难以制备的化合物如类固醇、生物碱、維 生素、核酸、酶和某些抗菌素等。用生物合成 法将 $\mathrm{C}^{14}$ 及 $\mathrm{H}^{2}$ (郎氞, 或称 D) 引入有机化合 物的方法，文献中已有很多，但用氛标記化 合物的报告还很少。最近 Dutten 等 ${ }^{[3]}$ 报告从 生长于含気水的营养液中的大豆分离出氞标 記的脂肪酸。Ober 等 ${ }^{[4]}$ 从含氛水的发酵液 中分离出抗菌素 Paromomycin。

用生物合成法可以合成目前人工难以合 成的很多化合物，而且产品是有旋光性的光 学异构体，不必再加分离，对于合成含許多 不对称碳原子的葯物特別有用。唯用生物合 成法时，同位素利用率很低，化合物收得量 也低。由于大量非标記化合物的稀释作用， 收得的产品比放射性也較低。这些缺点对于 $\mathrm{C}^{14}$-标記化合物的生物合成是很严重的。由 于氞水的价格很低，用生物合成法制备㐾标 記的葯物有时还是可行的。当然，用生物合 成法无法控制产品的氛的位置是一个缺点。

3. 氞气暴射标記法 近来交献中最常用 的为 Wilzbach ${ }^{[5]}$ 的氞化方法。此方法的原
理, 为几个居里气体氞的放射性, 可引起氞 与有机化合物分子中橅的交換反应。Wilzbach 最初所用的氞气暴射方法是将 $0.5-4.0$ 克的拟标記样品和 6-14 居里的气体氞, 在 密閉系統內混合，于室温下直接作用，使気 与化合物中的氢充分交換。一般需时 3-10 天，交換率为每天 $10^{-6}-10^{-2}$ 。 这种方法可 用于标記結构复杂、合成困难及街无他法合 成的䒺物，有时結构还不清楚的化合物和其 衍生物也可用此法标記。此法操作簡便，可 得大量的比放射性很高的标記葯物。

为了增加交換率, 縮短交換时間, 并減 少気的用量, 已有很多办法利用外界能量促 进这一标記过程。如利用放电、 $\gamma$-射綫、微 波及永一光敏反应等。但有时产生很多分解 产物。Mottlau 用贸或氮稀释气体氛，避兄了 分解产物的生成，得到放射性較高的产物。 氞气曝射标記法的另一缺点为不易进行特定 位置的标記。不过, 研究在不断进展, 現正 利用不同化学鍵对輻射的敏感性不同进行特 定位置的标記; 亦可将中閔体进行氞气曝射， 再結合化学合成进行特定位置的标記。可以 預見，利用 Wilzbach 法标記特定位置的問 題，在一定情形下是可以解决的。

氞气曝射法可用于固体和液体样品的标 記。一般于懪射后将多余的氞气移去, 使样 品在水或醇等含垟基的溶剂中結晶或沉淀, 以除去活泼的氛原子，再經过各种純化过 程, 直到样品的比活性不再改变为止。最后 仍須用杜层析、紙层析或区流分布分析等方 法，以确証放射性和原化合物的統一性。对 用 Wilzbach 方法制备的样品作这样严格的鉴 定是很必要的，因有时可由双鍵的袅化或由 放射化学反应产生微量化合物，这些微量杂 稹虽不能用一般分析方法測知，但可能包含 
了大部分的氛。Rosenblum 与 Meriwether ${ }^{[6]}$ 曾报告在将氢化可的松用 Wilzbach 法氞化 后，紙层析时得到两个放射性点，其中主要 的一个皖不吸收紫外光, 亦不能用显色反应 測知，可見含量很小; 而另一放射性較弱的 点則吸收紫外光, 乎与四唑（銔）呈显色反 应, 郎気标記的钅化可的松。已經証明所得 的微量杂稹是 4,5-二氢氢化可的松。

Spratt 与 Okita ${ }^{[7]}$ 应用的 Digitoxin $-\mathrm{H}^{3}$ 是 Wilzbach 代为标記的。他将 450 毫克非标記 的 Digitoxin 与 7.5 居里气体気密閉于玻璃反 应器內，使之作用 5.8 天。用乙醇洗去可交 換的氛后，再用层离杜提純。用乙醇一水及 氯仿一乙醚重結晶至恆熔点及恆比活性。刚 暴射后原样品的比活性达 513 微居里/毫克, 提純样品的比活性仍达 76.8 微居里/毫克。

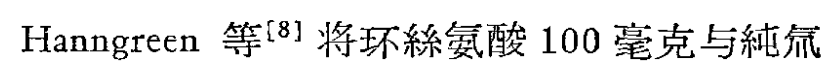
气体放入一密閉系統內, 在每秒 4 兆周的微 波作用下使之反应 5 分鈡。經提純后，得到 每毫克 55 微居里的氙标記的环絲氨酸。

\section{氞标記化合物的測定}

近年来気的所以广泛用于示踪工作，部 分原因为新的敏感測定方法的发展。因氞放 射的 $\beta$-粒子最大能量只有 $18 \mathrm{kev}$, 很难通过 計数管的云母窗。気测量的更重要的障碍是 无論标記样品怎样薄, 大部能量經自吸收而 消失。目前至少有两种方法可克服这些困 难, 郎气相計数和液体閃爍計数。在气相計 数时, 一般将样品燃烧成水, 然后将水轉化 为氫(気)气或其他气体(如甲烷), 再和适当 的計数气体混合后，利用 G-M 計数管計数。 这种方法虽所需样品不多, 計数效率高达 80-90\%, 也极灵敏, 但操作上䡆为复杂費 时, 限制了应用。今将液体閃爍計数法, 簡
单叙述如下:

1. 液体閃爍計数的原理 应用液体閃婂 計数法測定放射低能量 $\beta$-粒子的同位素, 是近几年来同位索技术重要发展之一 ${ }^{[9]}$ 。本 法的原理很簡单 ${ }^{[10]}$ : 将放射 $\beta$-粒子的标記 化合物溶于或混悬于一种介液, 当介液吸收 了 $\beta$-粒子后郎放出光子, 使一光电倍增管面 对介液的容器, 手与一計数系統相連, 郎可 記录因同位素的衰变而放出的 $\beta$-粒子, 这种 介液又称为閃㹸液, 一般含一种溶剂和两种 溶稹(第一溶稹和第二溶稹)。将标記化合物 溶于閃爍液后， $\beta$-粒子的能量郎由溶剂传于 第一溶稹。但第一溶稹放出的光子多与紫外 区相近, 不能直接測量。第二溶稹的功能是 轉換波长, 所以又称为波长轉換溶稹。这种 溶稹能吸收波长短的光子, 而放出波长較长 的光子。这两种溶盾通称为磷光体。因其放 出的磷光衰变时間极短, 仅为 $3 \times 10^{-9}$ 秒, 故可用于計数。

2. 溶剂因閃㮡液內溶剂的量最大, 选 择溶剂时必須考虑到純度和供应来源問題。 純度很重要, 因杂貭可能吸收光子, 产生所 謂猝灭現象。溶剂还必須不腐蝕样品的容器 如聚乙烯瓶等。最常用亦最有效的溶剂为甲 苯、二甲苯和三乙基苯等烷基苯。烷氧基苯 如甲氧基苯, 和醚类物貭如二氧杂环已烷也 很常用。这些溶剂中, 甲苯既便宜透明, 又 容易获得大量純品, 所以最为常用。最近, Faissner 等 ${ }^{[11]}$ 报告三种三甲基苯的混合物 Shellsol A 和十氫化荥的光輸出性能与甲苯很 相近, 而毒性和引火性則較小, 很可能作为 常用的閃爍溶剂。为了使所測的标記样品 (水溶及酯溶)和两种溶稹都溶解, 有时必須 用混合溶剂，如甲苯与醇、二氧杂环已烷与 嶚等。Hyamine 为一季胺, 能与很多酸性物 
稹形成能溶于甲苯的盐，所以在測定蛋白稹 及氨基酸类物貭时，常用 Hyamine 的甲苯溶 液作溶剂。很多碱性物稹如腺嘌哈和鳥便嘌 哈等，与 2-乙基己酸形成溶于甲苯的盐, 所 以2-乙基已酸的甲苯溶液常用为測定碱性物 稹的溶剂。近来在測定 $\mathrm{C}^{14}$ 及 $\mathrm{H}^{3}$ 时，常将 欲測样品氧化成 $\mathrm{C}^{14} \mathrm{O}_{2}$ 及 $\mathrm{H}_{2}^{3} \mathrm{O}_{0}$ 这样, $\mathrm{C}^{14} \mathrm{O}_{2}$ 可被 Hyamine 所吸收, 或以 $\mathrm{BaC}^{14} \mathrm{O}_{3}$ 形式作 悬浮計数; $\mathrm{H}_{2}^{3} \mathrm{O}$ 可溶于二氧杂环己烷。用这 种方法，在同一次实驗中分离出的不同化合 物，就可以同一种形式，在同一种溶剂中計 数了。虽然預备样品稍需些时間，但不仅方 便了溶剂的选择，而且可使不同化合物（样 品)的計数效率相同。

3. 第一溶稹 这类物盾的共同特点为以 直綫形式相联(而非形成稠环)，含有三个以 上的共䡉芳香环。 $\phi_{3}$ (对联三苯) 是最常用 的燐光剂之一。很多其他化合物曾試用作燐 光体，較常用者有 $\operatorname{PPO}(2,5$ 二苯基啞唑)及 PBD (2-(4一联苯基)-5-苯基-1,3, 4一堅二唑) 等。对这些化合物的很多衍生物曾进行过研 究，但能实际用作燐光体者，除有閃爍性能 外还必須具备溶解度高，价格便宜的条件。

4. 第二溶貭 光电倍增装置对第一溶貭 放出的光子敏感度很低，必須有第二溶貭将 光子波长轉換长些，才能較精确地測定。常 用的波长轉換剂有 POPOP (2,2-对一苯一撐双 (5一苯基烈唑)）；最近的报告指出二甲基一 POPOP 放出的光子波长更长些，而且在常 用溶剂中的溶解度較大，有希望能代替 POPOP。其他常用者有 $a-N P O(2-a-$ 羕-5 苯基堅唑)， $\boldsymbol{a}$-NOPON $(2,2$-对一苯撑一双一 (5- $\alpha$-嶚噁唑 $))$ 和 $\operatorname{DPH}(1,6$-二苯基1,3,5-已 三烯）。

这类化合物的命名法較为复杂，現在通
用簡写法，例如以 $\mathrm{P}$ 代表苯环，以 $\mathrm{N}$ 代表嶚 环，以 $\mathrm{B}$ 代表联(二)苯，以O代表 1,3-氧氮 杂茂等。

溶稹的浓度 第一溶稹为 4-15 克/升， 第二溶稹为 $0.05-0.5$ 克/ 升。一般浓度愈 大，效率愈高。但浓度的选择还要考虑溶貭 的溶解度和价格。为了測定 $\mathrm{C}^{14}$ 和 $\mathrm{H}^{3}$ 标記 的化合物，一种最常用的閃爍液是 4 克 PPO 和 0.1 克 POPOP 溶解于 1 升甲苯內。

5. 样品容器 当实驗条件齐备后, 拟測 样品的制备很簡便。只須将样品和燐光体溶 于选定的溶剂, 盛于适宜容器郎可計数。最 初用以盛标記样品和閃爍液的容器为 5-15 毫升的小玻璃拄。但一般玻璃皆含 $\mathrm{K}^{40}$, 其放 射性可增加計数的本底。所以必須用含鉀量 低的玻璃, 而且瓶愈小愈好, 瓿壁愈薄愈好。 此外，所有玻璃經光照后都发一定程度燐 光, 以紫外綫和可見光的短波 (蓝与紫)为最 明显。此光照活性，可由日光或日光灯照射 小㧚而产生，其襄退时間很长，如无适当措 施，可严重影响計数。

石英成分中无 $\mathrm{K}^{40}$ ，也沟有光照活性。不 过，石英制小㧚价值很貴，限制了广泛应 用。聚乙烯小瓶的本底計数很低，計数效率 很高，而且价格低廉。此外，聚乙烯小瓶可 以燃烧，方便了废物的处理。但是，聚乙烯 形瓦可被甲苯浸蝕，所以不能长时期存放样 品, 制好的样品必須尽早計数, 計数完毕師 应洗淨以备再用。这种小旡的另一缺点为遇 热郎变軟，所以，对于必須加热于能溶解的 样品不宜使用。

6. 仪器 閃炫計数仪的坠要部分为光电 倍增管。光子击中管中的阴极面时产生光电 子，光电子产生的电流經一系列装置可放大 $10^{5}-10^{6}$ 倍。但一般光电倍篦管的共同缺 
点为可产生噪声, 在管的輸出部位产生各种 大小的非光电电压。这种噪秒主要由热电子 而来。因噪卢本底很高（在测量 $\mathrm{C}^{1+}$ 及 $\mathrm{H}^{3}$ 的 条件下吅达 $10^{4}-10^{6} \mathrm{CPM}$ ), 且不恆定, 对仪 器的設計带来很多麻煩。为了減少噪声, 最 常用的方法为将仪器置于-摄氏零度以下的冰 箱闪計数，因冷却河減少热电子的产生。由 于多数热电子引起的电压小于光电子所产生 者, 在电路中加一鉴別器, 使只有电压超过 一定量 (如 $3 \mathrm{~V}-10 \mathrm{~V}$ ) 时才能通过, 亦可除 去大部噪声而不影响真正計数。在測量弱 $\beta$-射綫时, 需要更进一步地減少噪声, 最近 仪器中潦設的符合装置, 郎为此目的。符合 装置是两个光电倍增管以值角位置同时“看” 所測样品的装置。这两个光电管噪声的产生 是随机的, 而且是独立互不相依的。但這的 閃类計数, 則阿管同时发生。将两管晞出的 电压迭入适当綫路, 則可能只使符合电压通 过, 而除去大部随机噪声。除去噪声的另一 方法为尽量使加于光电管的高压低些。

此外, 在翰入定标器前仍需将液休除㡜 計数产生的电压作进一步鉴別, 以除去特大 的电压 (如 $100 \mathrm{~V}$ 以上的电压), 这些特大电 压，一般由宇宙䋐及环境周围的宮能 $\gamma$ 一射綫 而来，壇加了液体师㴪計数的本底。将噪声 和特大电压除去后, 再将脉冲翰入定标器, 就可記录中間能显 $(10-100 \mathrm{~V})$ 的脉冲了。

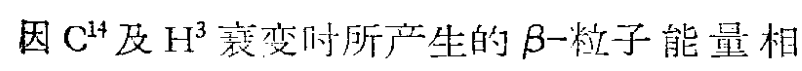
差很大, 如在骦入定标器前, 将中間能量的 脉冲再加鉴別，就可将 $\mathrm{C}^{1+}$ 及 $\mathrm{H}^{3}$ 双标記化合 物的放射性分別計数了。

\section{$\mathbf{H}^{3}$ 标記化合物在䓎理学确究中的应用}

当标記化合物进入机体后，从組織或体 液測得的放射性，不一定全部代表原来的化
合物。可見特异性测驗是一件很重要的工 作，但学被实驗者所忽視。測驗特异性最常 应用的方法为, 用紙层析法与已知結构的䒬 物比較 $R_{f}$ 值; 斾可用經典的同位素稀释法, 观察加入载体后能否重結晶至恆放射性; 另 一最适用的方法为与已知化合物比較在不同 溶剂对中的分配系数。

为了分离标記化合物, 常用柱层析或紙 层析方法。最近发展的薄板层析方法亦可应 用。因多数䒬物为弱酸性或碱性物稹，所以 亦可采朋液体一一液体提取法, 如反流分布 法。在这种工作中，最常遇到的問題为溶剂 的选择，这些是分离工作的关鍵性問題。 一般都尽量采用极性小，而可将葯物至部提 出的溶剂, 以減少提出代謝物的可能性。 代謝产物一般較原䒬物极性大，分离时宜用 較极性的溶济提取，或从水溶液中盐析分

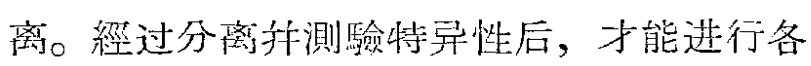
种研究。今将近年来 $\mathrm{H}^{3}$ 标記化合物在䒬理 学研究中的应用情况, 举例介紹如下:

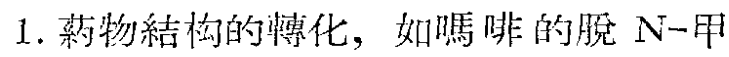
基。Elliot 等給动物注射 $\mathrm{N}-\mathrm{C}^{14}$-甲基嚅啡后， 从呼出气体中发現放射性二氧化碳, Axelrod 及 Herken 等报告嗎啡与肝組織在体外温畉学 店有甲醀逸出。这些作者从们推論嗎啡在体 內可以轉化成 $\mathrm{N}$-去甲基嗎啡。但从来还沒 有直接証据説明这个現象, 主要原因为所用 方法的敏感度和特异性㙂低。Misra 等 ${ }^{12-13]}$ 将 $\mathrm{H}^{3}$ 标記的嗎啡洼射給大鼠后，以紙层析 和同位素稀释法等从尿分离出 $\mathrm{N}$-去甲基嗎 啡, 㨁接証明了嗎啡在体队可以轉化为去甲 基雨啡的反应，并且还証明尿中有去甲基嗎 啡的結合物存在。

2. 小剂量䒬物在人体內的代謝。前已談 到以 $\mathrm{H}^{3}$ 作示踪的优点之一为可得比活性很 
高的标記化合物。因 $\mathrm{H}^{3}$ 放出的照射能量很 低，可以应用很大的放射剂量。利用 $\mathrm{H}^{3}$ 的 这两个优点, 可以在近乎生理剂量下研究腎 上腺素在人体的代謝。Axelrod 已經証明 3O-甲基化是大鼠轉化腎上腺素的一重要环 节，但实驗是用非标記化合物进行的，而且 所用剂量很大 (相当給一体重 70 公斤的人 1.4 克)。Labrosse ${ }^{[4,215]}$ 用比活性为 267 微居 里毫克的 $\mathrm{d} 1$ - 腎上腺- $7-\mathrm{H}^{3}$ 酒石酸盐重复了 这一工作, 而所用剂量則很小。他㑚 ${ }^{[15]}$ 还进一 步在人体研究了这一化合物的代謝, 而剂量 仅为 45 分鈡內静脉滴入 1 毫克。在給药后两 小时內收集的尿 0.1 毫升郎可得到 $8000 \mathrm{cpm}$; 后 24 小时尿 0.1 毫升的計数仍为 $200 \mathrm{cpm}_{\text {。 }}$ 他們发現 48 小时內自尿排出的放射性为剂 量的 73-95\%; 他們还証明 3-0-甲基腎上 腺素也是人轉化简上腺素的一重要环节, 此代謝物以未結合的，能被酸水解的，及与 葡萄糖醛酸結合的三种形式存在。 Labrosse 訩为利用比活性这样高的标記腎上腺素，可 以准确地測到 0.005 微克腎上腺素或其代謝 物，达到生物鉴定法所可能測定的范围。

毒毛旋花子苷的剂量也很小，在人体进 行其分布和排泄的研究原是很困难的。自 高放射性的氞标記化合物制成后，困难克服 了。例如 Dutta 及 Marks ${ }^{[16]}$ 以氧化白金为接 触剂, 进行毒毛旋花子葉的氛化。經一系列 純化手續得到的毒毛旋花子葉 $-\mathrm{H}^{3}$ （0.589 微 居里/微克) 和双氢瑇毛旋花子葉 $H^{3}$ (1.55 微 居里/微克)。他們証明給人靜脉洼射毒毛 旋花子葉 $-\mathrm{H}^{3}$ 后，血中的 $\mathrm{H}^{3}$ 水平先下降很 快，随后郎下降很慢。在进行心脏手术的病 人，他們还同时取样分析了动脉竇与冠状竇 中血的放射性。他們发現在給标記䒺物后的 16 分鈡內，心脏动脉血与青爭脉血的放射性，
有一定差异。差异程度和差异持續的时間与 病人事先应用毛地黄类䒬物的程度有关。他 們訩为, 給病人后, 毒毛旋花子苷很快为心脏 所摄取，其排泄主要經腎脏。最近 Dutta 等 ${ }^{177]}$ 还用大鼠和羊研究了毒毛旋花子葉 $-\mathrm{H}^{3}$ 和双 氢毒毛旋花子苗 $-\mathrm{H}^{3}$ 的分布和排泄。

3. 与代謝更新率有关的䃟究。內源性物 稹分泌进入血液后, 如代謝速度与合成速度 相等，則血液中該物稹的浓度可保持恆定。 如以示踪标記物稹标記血浆庫, 則血浆比活 性下降的速度，郎該物稹分泌进入血液的速 度，或更新速度。

Axelrod 等 ${ }^{[18]}$ 报告，給猫静脉注射腎上 腺素 $-\mathrm{H}^{3}\left(\mathrm{E}-\mathrm{H}^{3}\right)$ 后的几分鈡內，血浆的 $\mathrm{E}-\mathrm{H}^{3}$ 水本先有一快速下降，随師变为緩慢下降。 在䍃慢下降期, 血浆 $\mathrm{E}-\mathrm{H}^{3}$ 浓度的对数与时 間成值綫关系。最初几分鈡的快速下降是由 于扩散到組織, 及經 $\mathrm{O}$-甲基化轉变为 Metanephrine (M) 的結果; 随后的緩慢下降則由 于腎上腺素 (E) 从結合部位的释放或产生及 进一步的代謝 (标記的及非标記的) 所致。 因机体的 $\mathrm{E}$ 含量是固定的, $\mathrm{E}$ 的正常生成速 度, 可由 $\mathrm{E}-\mathrm{H}^{3}$ 下降曲綫的斜率求得 (郎可 求单位时間內血浆 $\mathrm{E}$ 被置換的百分数, 或新 生成 $\mathrm{E}$ 的百分数)。

但是应該指出，Pekkarinen 及 Lund 用螢 光光度法測定的研究只发現了第一相, 于是 以为注入体內的 $E$ 只在血浆內停留十分鈡左 右。而Axelrod 等的結果指出 $\mathrm{E}-\mathrm{H}^{3}$ 可在血浆 內停留很长时間。給猫靜脉注射 $\mathrm{E}-\mathrm{H}^{3}$ 后两 分鈡，血浆中 Metanephrine- $\mathrm{H}^{3}\left(\mathrm{M}-\mathrm{H}^{3}\right)$ 的水 本郎超过 $\mathrm{E}-\mathrm{H}^{3}$ 的水平。这一代謝物自血浆 消失的速度大致与 $\mathrm{E}-\mathrm{H}^{3}$ 者相同。

Muller 等 ${ }^{[19]}$ 利用醛固酮 $-\mathrm{H}^{3}$ 站明正常人 每天分泌醛固酮 $200 \gamma$, 而三个阿狄森氏病病 
人則每天分別分泌 $18 、 8$ 和 $30 \gamma$ 。另两个同 样的病人于应用 ACTH 后, 每天分別分泌醀 固酮 51 和 $185 \gamma_{\circ}$ 。

通过更新率的測定可以研究很多問題。 例如应用去甲基篮上腺素 $-\mathrm{H}^{3}\left(\mathrm{NE}-\mathrm{H}^{3}\right)$ 可以 比較不同組織合成 NE 的速度。同样，应用 标記的 5-䍩色胺、維生素 C、类固 醇激素 等, 可以研究这些內源性物稹在葯物作用下 的排泄或合成速度。例如已經証明用利血平 后, $\mathrm{NE}-\mathrm{H}^{3}$ 不再在組織中聚集, 而很快自机 体消失。关于 $\mathrm{E}-\mathrm{H}^{3}$ 及 $\mathrm{NE}-\mathrm{H}^{3}$ 在葯理学基本 理論中的应用，近年来已进行了大量工作。

4. 应用于䂠究影响中枢葯物的作用机 制。Axelrod 等 ${ }^{[20]}$ 报告, 給猫靜脉注射 $\mathrm{NH}-\mathrm{H}^{3}$ 后几分鈡內，心、脾及腎上腺中 $\mathrm{NE}-\mathrm{H}^{3}$ 的 水本最高, 肝胜者次之, 肌肉者最低。預先 給猫利血平、苯丙胺、Imipramine 及氯丙嗪 后，靜脉注射的 $\mathrm{NE}-\mathrm{H}^{3}$ (25 微克/丕斤, 3.44 毫居里/毫克）进入心肌、脾及腎上腺者大 为減少, 进入肝者減少不多, 进入肌肉者則 无变化。他們䚯为这是由于利血本等葯物改 变了这些組織神經末稍对 NE 的保护性結 合, 从而使 $\mathrm{NE}-\mathrm{H}^{3}$ 暴露于大量酶上, 促进了 代謝。

但这些药物的作用是不一样的, 可能由 于不同的机制影响 $\mathrm{NE}-\mathrm{H}^{3}$ 在組織中的水本, 而产生相同的結果。組織中 $\mathrm{NE}-\mathrm{H}^{3}$ 水本的 減少，可能由于葯物阻断了 $\mathrm{NE}-\mathrm{H}^{3}$ 的摄聚， 防止了与組織的結合，或促进了結合 $\mathrm{NE}-\mathrm{H}^{3}$ 的释放，或这些因素都参与了。Axelrod等 ${ }^{[21]}$ 証明利血平与苯丙胺能使結合的 NE 从儲存 点释放，因这些䒺物 无論在 $\mathrm{NE}-\mathrm{H}^{3}$ 注射前 或注射后給予大鼠，都使心脏的 $\mathrm{H}^{3}$ 含量減 少。但不能排除这些䒺物也有抑制心肌摄聚 $\mathrm{NE}-\mathrm{H}^{3}$ 的可能性。氯丙䅈、古柯碱和 Imi- pramine 等則只抑制組織对 $\mathrm{NE}-\mathrm{H}^{3}$ 的摄取, 阿不能促使結合 $\mathrm{NE}-\mathrm{H}^{3}$ 的释放，因这些葯 物只在注射 $\mathrm{NE}-\mathrm{H}^{3}$ 前給予动物，始能減少 組織中的 $\mathrm{NE}-\mathrm{H}^{3}$ 含量。如在注射后給予, 則无变化。

Wilson 等 ${ }^{[22]}$ 証明利血本亦抑制脑对 $\mathrm{E}-\mathrm{H}^{3}$ 改 $\mathrm{NE}-\mathrm{H}^{3}$ 的摄取。很多哳究証明，利 血平、苯丙胺和胍乙啶都能使心肌的 NE 減 少。最近 Potter 与 Axelrod ${ }^{[23]}$ 报告 MAO 抑制 剂 JB516 及澳贲乙胺能部分抑制利血平和胍 乙啶的这种作用，但不抑制苯丙胺的这种作 用。于是他們訩为利血平和胍乙啶所释放的 $\mathrm{NE}$ 可被 $\mathrm{MAO}$ 轉化，而拟交感胺則作用于 另一儲存庫, 其所释放的 $\mathrm{NE}$ 是被 COMT 所轉化的 (古柯碱可抑制拟交感胺的这种作 用）。这些研究都是用 $\mathrm{NE}-\mathrm{H}^{3}$ 进行的。

最近, Costa 等 ${ }^{[2+1}$ 給大鼠静脉注射 $\mathrm{NE}-\mathrm{H}^{3}$ 12-18 小时后，将心脏取出，进行葯物灌 流，并比較加葯前后灌流液中的放射性。如 于每分鈡灌流利血本 $10 \gamma$ ，則灌流液的放射 性增加三倍, 且增加的物貭是有酸性的。在 灌流液中加入胍乙啶（10 r/分），亦可使灌 流液的放射性增加三倍，但所增加者大部是 碱性物盾。于是他們訩为利血本和胍乙啶使 心肌释放 NE 的机制是不同的，前者释放 $\mathrm{NE}$ 于 $\mathrm{MAO}$,而后者释放 NE 于受体。

5. 应用于去神經器官对儿茶酚胺的敏感 性的研究。去掉交感神經的器官对儿茶酚胺 的敏感性增加是久已公䚯的事实。但对这一 現象很久沒有确切的解释。Herting 等 ${ }^{[25]}$ 报 告，猫去掉右頸上神經节后的組織当天結合 $\mathrm{NE}-\mathrm{H}^{3}$ 和 $\mathrm{E}-\mathrm{H}^{3}$ 的能力虽无明鼠改变, 但 經 5-21 天后，則結合能力明显下降。Axelrod 等會指出，与組織結合是儿茶酚胺失活的一 个主要机制，去神經后这一失活机制郎无从 
进行，較高浓度未結 合的有活性的儿茶醇 胺，与去神經的受体作用时間延长，于是产 生敏感性。Whitby 等 ${ }^{[26]}$ 报告古柯碱能減少組 織从循环摄聚儿茶酚胺 (郎減少結合), 因 而亦增加組織的敏感性。

6. 药物与亚細胞成分的結合。Potter 和 Axelrod ${ }^{[27]}$ 給大鼠靜脉注射氛标記的 NE、E、 Dopa 及 Dopamine 后, 将心脏磨成与浆, 分 开各亚細胞成分，分別用䖝光法及測放射性 的方法測定各成分中的儿茶酚胺。他們証明 內源性和筷标記的 $\mathrm{NE}$ 及 $\mathrm{E}$ 主要存在于微粒 体部分, 細胞核和心肌殘渣的含量很少, 綫粒体內几乎不含。但氞标記的 Dopa 及 Dopamine 完全在上清液部分。在腎上腺髓 稹里, 大部分內源性儿茶酚胺及所有 $\mathrm{E}-\mathrm{H}^{3}$ 和 Dopamine- $\mathrm{H}^{3}$ 都在离心管底部的較大顆粒 中，而 $\mathrm{NE}-\mathrm{H}^{3}$ 則主要在微粒体部分。可見， 心肌的 NE 支 $E$ 虽在細胞的同一成分內, 但 腎上腺里的 $\mathrm{NE}$ 和 $\mathrm{E}$ 則在細胞的不同部位。 腎上腺里的 Dopa- $\mathrm{H}^{3}$ 則只在上清液部分。

最近, Mirkin 和 Gillis ${ }^{[28]}$ 用密度差离心 法研究了 $\mathrm{NE}-\mathrm{H}^{3}$ 在大鼠脑匀浆成分內的分 佈，手且証明預先以利血平处理大鼠，可以 改变这种分佈。

7.激素蛋白稹代謝的研究。小分子量激 素如类固醇激素的代謝研究虽很多, 但关于 蛋白稹类激素的代謝命运則所知很少。主要 原因之一为无适当方法标記激素蛋白, 先用 $\mathrm{C}^{14}$ 标記氨基酸, 再用生物合成法制备的胰 島素比放射性很低, 无法应用。Stadie 等曾 合成了胰島索的带 $\mathrm{S}^{35}$ 标記的硫酸酯; Lee 制 备了 $I^{131}$ 标記的胰島素衍化物。但这些化合 物所含的标記原子 $\left(\mathrm{I}^{131}\right)$, 或含标記原子的基 团 (硫酸 $-\mathrm{S}^{35}$ ), 都是渎島缶分子本身所不含 有的。因为小心制备的胰島素 $-1^{131}$ 粍不失其
生物活性 (小鼠凐攣), 所以僠用于研究工 作。不过, 很多学者指出, 用磑化蛋白稹所 得結果有时是无法解释的。如 Margen与 Tarver 就賏指出这种蛋白可在体內脫碘, 而 不伴有肽鍵的水解。再者, 汶样标記的蛋白 稹生物活性有时是难于保証的，其代謝命运 可能与不标記的已知有生物活性的蛋白稹分 子不同。

Holt 等 ${ }^{[29]}$ 使 1 克胰島素結晶 (23国际单 位/毫克, 含鋅 $0.62 \%)$ 与 2.18 居里気气体 在室温下作用 2 周, 經 6 次重結晶后, 得到 比活性为 4.6 微居里/毫克的胰島素 $-\mathrm{H}^{3}$ 。 他 們証明这种标記化合物的降血糖活性, 及与 大鼠膈肌的亲合力, 和标准品者相同。他們 发現, 給大鼠静脉注射后两小时, 胰島素 $-\mathrm{H}^{3}$ 与垂体、腎上腺及肝蛋白結合得很多, 脑的放射性則很低。酸溶部分的活性以腎与 肝最高, 而垂体与腎上腺很低。他們䛦为, 垂体及腎上腺蛋白和胰岛素 $-\mathrm{H}^{3}$ 的高亲合 力, 可能表示费岛素对腎上腺伎垂体激素的 生物合成有关。

利用気标記其他激素蛋白或有生物活性 的多肽, 进行各种代謝研究, 必将日盆增 加, 使激素䒺理学和內分泌学更加丰富。

8. 氞放射自显术在䒺物分布研究中的应 用。研究标記䒬物的分布时最常用的方法 为, 将各組織取出, 經一定处理后, 用計数 器測其放射性。这种方法的优点为准确, 且 可定量。但䒺物在任何一种組織的分布，不 一定是均匀的, 而所測結果为一本均值。此 外，自吸收的校正，样品的处理，和化合物 的分离提取等，手續很麻煩。

放射自显术在药理学硑究中应用得还很 少。主要原因之一为䒺物多可溶于水和固定 液。用一般的組織学方法, 在切片的化学固 
定和脫鋢过程中，标記化合物有轉移或王失 的危险。近来，Ullberg ${ }^{[30]}$ 在快速冰冻状态下 将整体动物作成 $10-20 \mu$ 厚的切片, 克服了 上述缺点。気的放射能量很低，測其放射性 虽較难，但对放射自显杢則是一优点，因其 分辨力很高。如将动物在給䒺后不同时間于 不同深度作成切片，就可覌察各种器官和組 織中同位素分布的动态变化。甚至內分泌系 統的各部、眼的各种組織、鼻甲、牙和牙周 的組䢂、皮肤、骨髓和关节等处同位素的分 布，亦可一目了然。体液中的同位素可在原 处出現。用怀孕动物制成的放射自显影，可 比較同位素在母体、胎盘、羊膜液和胎儿体 內的浓度。这种放射自显影很易制备, 除需 一冷冻室和一些于冰外，不需特殊設备。

若标記化合物在体內可以轉化，則含同 位素的轉化产物亦在自显影上出現。如想知 道原标記䒬物的含量, 可选择一定器官和組 織进行微量分离。从冰冻动物取出組織进行 分析，結果准确，可保証无污染的可能。郎 使是代謝速度很快的药物, 于动物快速冰冻 后，亦无违一步改变或轉运的可能。

若想定量比較各組織的放射性，可将切 片各部分分开計数, 或与标准比較自显影顏 色的深线，亦可比較片上感光的顆粒。如将 組織作成超微切片，則放射自显术可与电子 显微鏡結合使用，以进行更細致的分析。

利用氛标記䒺物进行放射自显影研究者 已很多。例如 Hanngren ${ }^{[3.1}$ 用氛标記的对 氨 基水楊酸 $\left(\mathrm{PAS}-\mathrm{H}^{3}\right)$, 証明 PAS 选择性地聚积 于甲状腺。这一現象可能与 PAS 能阻抑甲 状腺对放射性碘的摄取，及长期大量应用 PAS 可产生甲状腺肿等有关。这是通过㸴究 一种氛标記抗菌䒺的放射自显影, 发現与其 瑇性有关的綫索。
近年来, 由于标記 $\mathrm{NE}$ 的应用, 对于这 一神經介盾的分布、代謝和排泄积累了大量 資料。Whitby 等已經証明注射入机体的 $\mathrm{NE}$ 一部分被組織摄取而儲存相当长的时間, 且 儲存的 NE 可因刺激交感神經而释放。于 是, Hertting 等訩为交感神經末梢是注入 $\mathrm{NE}$ 的摄聚和儲存处所。Samorajski 与 Marks 曾 用放射自显术証明，将気标記的 NE 注射于 小鼠后, 下視丘的正中隆凸放射性很強。最 近这些作者及証明, 預先以利血平处理小鼠 可使正中隆凸（特別是邻垂体的后部）的放 射性減少。古柯碱的这种作用更強。Marks 等用闰样方法还証明, 刚洼射后的几分鈡內 $\mathrm{NE}$ 与儲存部位的結合科不明显, 但几小时 后則很明显, 并且指出 $\mathrm{NE}-\mathrm{H}^{3}$ 与心肌、脾、 小腸及腎的結合部位正是交感神經节后䊹維 的神經末梢。在腎上腺內, 髓稹的放射性很 強，但皮稹則无放射性。

因得标記的胸腺嘧啶核苷和胞嘧啶核苷 等可以参大核酸, 很多作者 ${ }^{[32]}$ 用这些标記的 核酸前身, 結合放射自显影, 研究各种細胞 如造血細胞和肿溜細胞 (多用 Hela 細胞) 等 分裂旺盛細胞的 RNA 和 DNA 代謝与細胞 分裂的关系。当然, 这种方法可用于研究抗 肿瘤菞物对核酸代謝和細胞分裂的影响。

此外, 結合放射自显影, Andre ${ }^{[33]}$ 研究 了氛标記的双氢鋉露素和四圆素在体內的分 布; Hanngren 等 ${ }^{[8]}$ 观察了环絲氨酸的分布; Smith 和 Fozzard ${ }^{\left[{ }^{[3]}\right]}$ 結合电子显微鏡和放射自 显影研究了异垟基洋地黄毒菑- $\mathrm{H}^{3}$ (Digoxin$\mathrm{H}^{3}$ )在心肌細胞內的分布; Moutschen-Dahmen 等 ${ }^{[35]}$ 㸴究了 Myleran- $\mathrm{H}^{3}$ 在細胞核內的 集聚。应該指出, 以上所举科不全面。

9. 其他关于 $\mathrm{E}-\mathrm{H}^{3}$ 和 $\mathrm{NE}-\mathrm{H}^{3}$ 代謝的报 告还很多, 而且日益增加。此外, Mayer 
报告了 Dichlorisoproterenol- $\mathrm{H}^{3}$ 的生理处置; Misra 等报告了去甲基嗎啡- $\mathrm{H}^{3}$ 的代謝; Roth 等报告了关于密而通 $-\mathrm{H}^{3}$ 的研究; Mellett 及 Henderson 与 Denham 分別研究了抗肿瘤葯 物 Cytoxan $-\mathrm{H}^{3}$ 和 Methotrexate $-\mathrm{H}^{3}$ 的代謝; Johns 等哳究了叶酸- $\mathrm{H}^{3}$ 在人体的代謝; Florini 等报告了合成类固醇氟垟強的松 龙 $-\mathrm{H}^{3}$ 的吸收、分布、排泄和代謝产物的研究。当 然，这种非全部交献。

$$
* * *
$$

綜上所述，自液体閃爍計数方法和氙气 曝射标記法发展后，很多以前不能进行或不 易进行的研究, 現在得以开展或易于开展; 以前解决得不够完善的閭題, 目前有可能較 完善地迸行了。虽然液体閃爍訐数法和気气 暴射标記法目前仍各有一定限制，相信在这 方面会有极迅速的发展，氛标記化合物不仅 在䒬理学哳究中的应用，将日湓增多，在其 他基础医学庋生物科学領域的研究上，亦将 日趋普遍。

[1] Sheppard H., Mowles T. F., Bowen N., Renzi A. A. and Plummer A. J., Toxicol. Appl. Pharmacol., 2, 188 (1960).

[2] Parke D. V., Pollock S. and Williams R. T., J. Pharm. Pharmacol., 15, 500 (1963).

[ 3 ] Dutton H. J., Jones E. P., Scholfield C. R., Chorney W. and Scully J., J. Lipid Research, 2, 63 (1961).

[4] Ober R. E., Fusari S. A., Coffey G. L., Gwynn G. W. and Glazko A. J., Atomlight, 22, 3 (1962).

[5] Wilzbach K. E., J. Am. Chem. Soc., 79, 1013 (1957).

[6] Rosenblum C. and Meriwether H. T., Proc. Symp. on Advances in Tracer Applications of Tritium, p. 3, 1958.

[ 7 ] Spratt J. L. and Okita G. T., 2nd. U. N. Intern. Cont. on Peaseful Uses of Atomic Energy, 25, 186 (1958).

[8] Hanngren H., Hansson E. and Ullberg S., $A n$ tibiotics and Chemotherapy, 12, 46 (1962).

[9] Maikel R. P. and Weissbach H., Ann. Rev.
Pharmacol., 2, 399 (1962).

[10] Bell Jr., C. G. and Hayes F. N., Liquid Scintillation Counting (Pergamon Press, New York) (1958).

[11] Faissner H., Ferreno F., Ghani $A$ and Reinharz M., Nucleonics, 21, 50 (1963).

[12] Misra A. L., Mule S. J. and Woods L. A., Nature, 190, 82 (1961).

[13] Misra A. L., Jacoby H. I. and Woods L. A., J. Pharmacol., 132, 317.

[14] Labrosse E. H., Proc. Symp. on Advances in Tracer Applications of Tritium, 1958.

[15] Labrosse E. H., Axelrod J., Kopin I. J. and Kety S. S., I. Clin. Invest., 40, 253 (1961).

[16] Dutta S. and Marks B. H., Biochem. Pharmacol., 12, 32 (1963)

[17] Dutta S., Marks B. H. and Smith C. R., J. Pharmacol., 142, 223 (1963).

[18] Axelrod J., Weil-Malherbe H. and Tauchick R. J. Pharmacol., 172, 251 (1959).

[19] Muller A. F., Veyrat R. et Manning E. L., Helv. Med. Acta, 26, 714 (1959).

[20] Axelrod J., Whitby L. G. and Hertting G., Science, 133, 383 (1961).

[21] Axelrod J., Hertting G. and Potter L., Nature, 194, 297 (1962).

[22] Wilson C. W. M., Murray Q. W. and Titus E. O., J. Pharmacol., 135, 11 (1962).

[23] Potter L. T. and Axelrod J., J. Pharmacol, 140, 199 (1963).

[24] Costa E., Nash C. W. and Brodie B. B., Biochem. Pharmacal., 12 (Supplement), 65 (1963).

[25] Hertting G., Axelrod J., Kopin I. J. and Whiltty L. G., Nature, 189, 66 (1961).

[26] Whitby L. G., Nature, 187, 604 (1960).

[27] Potter L. T. and Axelrod J., Nature, 194, 581 (1962).

[28] Mirkin B.'L. and Gillis C. N., Biochem Pharmacol., 12, 1173 (1963).

[29] Holt C. V., Nolte I. and Holt L. V., 2nd. U. N. Intern. Cont. Peaseful uses of Atomic Energy, 25, 230 (1958).

[30] Ullberg S., Biochem. Pharmacol., 9, 29 (1962).

[31] Hanngren A., Acta Radiol., Suppl., 175 (1959).

[32] Feinendegen L. E., Pond V. B., Shreeve W. W. and Paintèr R. B., Experimental Cell Research, 19, 443 (1960).

[33] André T., Acta Radiol. Suppl., p. 142 (1956).

[34] Smith J. R. and Fozzard H. A., Nature, 197. 562 (1963).

[35] Moutschen-Dahmen J. \& M., Verby W. G. and Koch G., Exptl. Cell Resenrch, 20, 585 (1960). 